\title{
Торговая политика Республики Корея: выбор оптимальной траектории либерализации
}

Проанализировано, как участие Республики Корея в системе ГАТТ/ВТО способствовало ее экономическому успеху, какие внутренние и внешние экономические причины заставили правительство этой страны отдать предпочтение региональному варианту либерализации в начале XXI в. Рассмотрены обстоятельства внешней и внутренней среды в настоящее время, дополнительные возможности максимизации экономических выгод от многосторонней системы регулирования торговли, в связи с которыми корейские власти уделяют больше внимания вопросам многосторонней либерализации, чем в последние несколько лет, а также перспективы дальнейшего усиления региональной составляющей корейской торговой политики.

Ключевые слова: торговая политика, ВТО, соглашения о свободной торговле, Республика Корея.

\section{Введение}

Опыт Республики Корея позволяет утверждать, что торговая политика может служить достижению целей развития и повышению уровня благостояния нации. На протяжении нескольких десятилетий второй половины XX - начала XXI в. южнокорейское государство последовательно стремилось максимизировать экономические выгоды от внешней торговли и исходя из этого определяло для себя оптимальную траекторию ее либерализации. Приоритет отдавался то многостороннему, то региональному формату в зависимости от конкретной ситуации. Именно тот факт, что торговая политика была интегральным элементом стратегии экономического развития, позволил Республике Корея достичь значительных успехов в повышении уровня жизни населения, сформировать и защитить национальный про-

1 Сутырин Сергей Феликсович - заведуюший Кафедрой мировой экономики Санкт-Петербургского государственного университета (СПбГУ), доктор экономических наук, профессор; руководитель проекта «Кафедра ВТО в СПбГУ»; Коргун Ирина Александровна - стариий научный сотрудник Азиатско-Тихоокеанского научного иентра Университета Ханбян (Сеул, Республика Корея), кандидат экономических наук. 
мышленный сектор, а также создать комфортные условия для конкуренции отечественного бизнеса на международных рынках.

В современной быстро глобализирующейся мировой экономике государства вынуждены функционировать в условиях жесткой конкуренции и отвечать на различные порождаемые ею вызовы, в том числе в области обеспечения экономической безопасности и поддержания приемлемого уровня благосостояния населения. Одним из инструментов, призванных решать возникающие в связи с этим проблемы, является торговая политика. В силу своего ярко выраженного перераспределительного характера она, как справедливо отмечает ряд исследователей [14], позволяет достаточно обоснованно судить о том, в какой мере правительство соответствующей страны ориентировано на максимизацию уровня благосостояния своих граждан.

О важности торговой политики, как известно, писали еще меркантилисты. Они считали, что страна должна с помощью активного протекционизма наращивать экспорт и минимизировать импорт с целью аккумулирования в стране золота, являвшегося, по их мнению, воплощением общественного богатства. Занимая диаметрально противоположную позицию в отношении конкретного содержания торговой политики и обосновывая целесообразность фритредерства, А. Смит и Д. Рикардо тем не менее видели в нем один из факторов увеличения «богатства нации». В вышедшем в 1844 г. эссе Дж.С. Милль дает положительный ответ на вопрос «способна ли отдельная страна посредством своего законодательства обеспечить себе большую часть выгод от внешней торговли чем та, которая была бы ей доступна в случае естественной либо спонтанной торговли» ${ }^{1}$.

В современной экономической литературе разработка проблемы взаимосвязи торговой политикой и эффектов внешнеторговых связей представлена, в частности, в трудах К. Багвела и Р. Стайгера [4], а также Дж. Гроссмана и Э. Хелпмана [15]. Они отмечают, что при разработке торговой политики правительства могут идти дальше экономических целей и включать в качестве составляющей политико-экономические предпочтения. При этом именно сочетание экономических и политических ориентиров во многом определяет, в какой мере государство отдает предпочтение многостороннему либо региональному формату либерализации торговли.

Некоторые авторы отмечают, что включение политической составляющей в торговую политику в значительной степени обусловлено уровнем развития страны. На ранних этапах развития, когда ее политическое влияние невысоко, государство руководствуются преимущественно целями экономиче-

$1 \quad$ Mill J.S. Of the Laws of Interchange between nations; and the Distribution of the Gains of Com-merce among the countries of the Commercial World. London Parker. Цum. no: [20]. 
ского развития и стремится максимизировать соответствующие макроэкономические показатели [22]. По мере укрепления международных позиций правительство обращает больше внимания на эффективность сотрудничества, активное продвижение собственных ценностей и интересов, нередко обусловленных политическими соображениями. С точки зрения указанных изменений во взглядах на торговую политику Республика Корея представляет собой хороший пример. За последние 60 лет она превратилась из бедной страны в развитую, сумев, в том числе и с помощью торговой политики, значительным образом повысить уровень благосостояния населения.

Следует отметить, что в современной системе мирохозяйственных связей, характеризующейся многообразием форм внешнеэкономической зависимости стран друг от друга, политика в духе классического жесткого протекционизма вряд ли возможна. В частности, формирование глобальных производственных систем делает импорт и экспорт жизненно необходимыми для нормального функционирования национальных экономик. Данное обстоятельство создает дополнительные условия для либерализации торговли в целях облегчения движения узлов, деталей, комплектующих между отдельными звеньями производственных систем. Основной вопрос, который приходится сегодня решать регуляторам, заключается не столько в том, либерализовать торговый режим или нет ${ }^{1}$. Проблема, скорее, состоит в том, на каком из вариантов либерализации - многостороннем в рамках Всемирной торговой организации (ВТО) или региональном в рамках соглашений о свободной торговле $(\mathrm{CCT})$ и таможенных союзов $(\mathrm{TC})^{2}-$ сделать основной акцент и как наилучшим образом совместить их друг с другом.

1 Преимущества более свободной торговли подтверждены многочисленными эмпирическими исследованиями, например [13; 48]. Родрик [41] критикует некоторые из данных исследований, но в иелом также признает важность более свободной торговли, одновременно указывая на значимость институциональных факторов экономического роста.

2 В данной статье авторы сознательно «вынесли за скобки» своего анализа вариант односторонней тиберализации. Известно, что определенная группа авторов именно ему отдает предпочтение. Его реализаиия не требует сложных и порой очень длительных межднародных торговых переговоров. Кроме того, нередко можно прочесть, что именно односторонняя либерализачия обеспечивает наиболее масштабные и разнообразные выгоды от торговли. Известность получил иллюстрирующий эту мысль акроним Л.А. Винтерса WYDIWYG - What you do is what you get [56]. Вместе с тем и в теоретическом, и в практическом плане преимущества односторонней тиберализации обоснованно ставятся под сомнение. В случае же Республики Корея следует отметить, что она использовалась в весьма ограниченных размерах, прежде всего в ходе подготовки к вступлению в Организаицю экономического сотрудничества и развития (ОЭСР). 
Вопрос о соотношении многостороннего и регионального форматов регулирования международной торговли в целом и ее либерализации в частности активно обсуждается в экономической литературе. Один из авторов настоящей статьи уже рассматривал состояние дискуссии по данной проблеме применительно к периоду конца прошлого - начала нынешнего веков [52]. За прошедшее с той поры время единства взглядов по-прежнему достичь не удается.

Одна группа ученых не видит проблем в одновременном существовании многостороннего и регионального режимов регулирования. Такую точку зрения высказывает, например, И.С. Ли: «Сегодня региональные системы торговли, в основе которых лежат ССТ, составляют неотъемлемую часть всемирной торговой системы... ССТ скорее всего будут не препятствовать, а способствовать многостороннему регулированию» [32, р. 129]. Аналогичного мнения придерживается И. Леджаррага, подчеркивая, что многие положения региональных торговых соглашений восходят корнями к многосторонним дискуссиям и, следовательно, способны укрепить существующие многосторонние обязательства [33, p. 7-8]. Официальная корейская позиция заключается в том, что региональные соглашения и ВТО являются не противоречащими друг другу, а дополняющими друг друга формами либерализации [27, р. 1]. По мнению некоторых исследователей [39; 19], для Кореи важны оба направления, так как они преследуют схожие цели: открыть доступ на иностранные рынки и тем самым увеличить объемы экспорта, а также защитить отечественных производителей от нечестной конкуренции либо действий иностранных правительств. Сочетание двух направлений либерализации позволяет избежать поспешных решений по чувствительным вопросам, например связанных с сельским хозяйством, и достичь большей эффективности мер на макро- и микроуровнях. Следует отметить, что не только Республика Корея рассматривает два направления либерализации в качестве дополняющих друг друга. Такой подход свойствен многим азиатским странам, до некоторой степени он является отличительной чертой «азиатского регионализма» [35].

Другая группа исследователей, наоборот, видит в ССТ препятствие на пути эффективного функционирования многосторонней системы ВТО. Так, Ч. Дент приходит к выводу, что распространение ССТ существенным образом подорвало те усилия, которые предпринимались для завершения Дохийского раунда ВТО. Более того, регионализация может негативно повлиять на международную торговую систему и в долгосрочной перспективе [11]. В мировом академическом сообществе существует немало приверженцев многостороннего формата либерализации торговли. Среди них можно отметить таких авторов, как Д. Браун, А. Дердофф и Р. Стерн [6], а также Ш. Армстронг [3].

Свою лепту в дискуссию внесли и эксперты ВТО. Аналитическая часть «Доклада о мировой торговле» за 2011 г. была посвящена именно этому вопросу. Отмечая серьезные противоречия между многосторонним и региональным подходами к регулированию международной торговли, авторы ставят зада- 
чу достижения в данной области «согласованности» в функционировании этих двух уровней [57]. Добиться этого далеко не просто. Дж. Бхагвати еще в 1995 г. подчеркивал, что «ССТ совмещают в себе свободную торговлю и защиту одновременно. Именно по этой причине они могут одновременно создавать преференции и дискриминировать» $[5$, р. 2, 7]. Отметим, что подобная амбивалентность во многом способствовала широкой популярности ССТ.

Одним из факторов успешного функционирования экономики Республики Корея стало умелое сочетание обоих форматов внешнеторговой либерализации. Отдавая в зависимости от конкретных условий и обстоятельств приоритет то одному, то другому варианту, власти страны смогли реализовать многие из поставленных целей социально-экономического развития. Ниже представлен анализ торговой политики Республики Корея, осуществляемый в контексте поиска и поддержания ею наиболее выигрышного сочетания многостороннего и регионального подходов к регулированию международной торговли.

\section{Корея в эпоху ГАТТ: «торговая политика развития»}

Экономические успехи Кореи в повышении уровня экономического развития, улучшении структуры промышленности, обеспечении конкурентоспособности национального бизнеса в немалой степени стали возможны благодаря грамотной торговой политике. Уже на ранних этапах своего формирования в 1960-е годы. она учитывала приоритеты развития и интересы корейских компаний. Последние, стремясь выходить на внешние рынки, широко практиковали поставки товаров по демпинговым ценам ${ }^{1}$. Корейские власти фактически поощряли подобную практику и находили различные способы возместить бизнесу понесенные убытки. Среди наиболее распространенных мер - разрешения на импорт узкой номенклатуры иностранных потребительских товаров и ресурсов, цены на которые на внутреннем рынке были существенно выше мировых, выдача кредитов на льготных условиях и проч.

В целом вплоть до образования ВТО корейская торговая политика была построена таким образом, чтобы поощрять расширение экспорта и ограничи-

1 Несмотря на то что первые законы, направленные против этого вида недобросовестной конкурениии, были приняты еще в начале ХХ в. (в Канаде в 1904 г., в Новой Зеландии в 1905 г., в Австралии в 1906 г., в Южной Африке в 1914 г., в США в 1916 г.), их повсеместное активное применение началось существенно позже, по мере того как переговоры в рамках ГАТТ стали приводить ксущественному снижению уровня тарифной защиты. Более того, как показывают исследования, вплоть до начала 1980-х годов большинство антидемпинговых расследований не приводили к введению соответствующих пошлин [21]. 
вать импорт потребительских товаров. Некоторые авторы характеризуют ее как неомеркантилистскую [11, p. 132] либо приравнивают к экономическому национализму [31].

Членство Кореи в ГАТТ, к которому страна присоединилась в 1967 г., не препятствовало, а наоборот, в силу ряда обстоятельств способствовало проведению подобной политики. В частности, общая система преференций (ОСП) открывала корейским товарам доступ на рынки экономически развитых государств, тем самым обеспечивая условия для наращивания экспорта. В данной ситуации ограничения для этого создавались прежде всего внутренними условиями производства. На улучшение последних и была направлена торговая политика.

Участие в ГАТТ в статусе развивающейся страны фактически избавляло Корею от обременительных обязательств по либерализации торгового режима и предоставления сопоставимых условий доступа на свой внутренний рынок другим участникам соглашения. Поэтому Корея могла активно применять различные меры защиты национальных производителей в тех секторах экономики, которые выбирались в качестве приоритетных. Здесь будет уместно привести следующий пример. Средний уровень эффективной таможенной защиты в тяжелой и химической промышленности в 1970-е годы, когда эти отрасли развивались в рамках стратегии импортозамещения, составлял $43,2 \%$. Как таковой он более чем в 10 раз превышал уровень защиты в экспортноориентированных отраслях легкой промышленности, равный $3,6 \%$ [49, p. 102]. В 1988 г., уже после того как Корея под давлением США и Западной Европы приняла ряд мер по либерализации собственного торгового режима, число связанных тарифных линий составляло не более $11 \%$ [Ibid.].

В целом значение членства в ГАТТ для Республики Корея состояло в расширении торговых возможностей и обеспечении условий для создания отечественной обрабатывающей промышленности. Сам факт принадлежности к международной торговой системе уже на ранних этапах экономического развития и формирования торговой политики позволил Корее интегрироваться в глобальные производственные системы в тот момент, когда они проходили начальные стадии своего становления [12; 18]. В результате корейская промышленность получила шанс развиваться в основном русле мировых тенденций. Это обстоятельство было особенно важно для таких отраслей, как автомобиле- и машиностроение, электроника, т.е. тех видов производств, которые в ходе развертывания процессов интернационализации и глобализации получили возможность перемещать отдельные стадии производственного цикла на территорию других стран.

Следует отметить, что в ГАТТ активность в плане участия в переговорном процессе и выдвижении собственных инициатив Республики Корея была довольно низкой [49, р. 407]. Такая ситуация сохранялась вплоть до середины 1980-х годов и стала меняться с началом Уругвайского раунда. Причиной 
тому послужило давление США и ряда государств Западной Европы на корейское правительство с требованием облегчить доступ для иностранных товаров. Для Соединенных Штатов важно было сократить дефицит, накопившийся у них в торговле с Кореей. Меры давления, применявшиеся США и их партнерами, сводились к инициации антидемпинговых расследований и навязыванию корейской стороне добровольных ограничений экспорта. Под них попали такие товары, как текстиль, цветные телевизоры, сталь и др. Наибольшее число ограничений было принято в отношении экспорта в США (68), Австралию (50) и ЕЭС (26) [1, p. 13]. В 1990 г., когда пик подобных мер уже прошел, Корея по-прежнему сохраняла 13 добровольных ограничений экспорта [Ibid., p. 12-14].

Можно утверждать, что указанное давление не просто было воспринято корейской стороной крайне негативно, но и вызвало пересмотр отношения страны к системе международной торговли в целом и принципам выработки торговой политики в частности. Это нашло проявление в том, что в ходе Уругвайского раунда Корея предприняла максимум усилий для защиты интересов страны и собственного бизнеса. В данном плане наибольшее значение имели несколько обсуждавшихся вопросов. Прежде всего следует назвать меры защиты сельского хозяйства, которое в Корее традиционно в силу ряда географических и исторических обстоятельств отличается относительно низкой конкурентоспособностью. Кроме того, особое внимание привлекали доступ на рынки несельскохозяйственной продукции (NAMA) и механизм разрешения споров. Создание последнего было для Республики Корея особенно важно, так как позволило защитить национальные компании от неправомерных действий более сильных с экономической точки зрения партнеров.

Общая переговорная стратегия Кореи в рамках Уругвайского раунда состояла в том, чтобы сохранить статус развивающейся страны в сельском хозяйстве и секторе услуг, тем самым обеспечив себе более длительные сроки и меньший уровень либерализации. Одновременно в части обязательств по доступу на рынки промышленной продукции корейская сторона стремилась солидаризироваться с развитыми странами с целью добиться максимально выгодных условий для международной деятельности своих промышленных компаний.

В целом корейской делегации удалось добиться на переговорах поставленных целей и фактически обеспечить себе искомый «двойственный» статус. Либерализация ряда сельскохозяйственных товаров - говядины, риса, красного перца, мандаринов и проч. - была отложена, тогда как общие сроки либерализации рынка сельскохозяйственной продукции и сокращения мер поддержки равнялись срокам, установленным для развивающихся стран. В отношении промышленных товаров обязательства Республики Кореи мало отличались от обязательств США, Японии или ЕЭС. Большое значение имело то, что корейская сторона присоединилась к Соглашению по информационным технологиям, устанавливавшим ставки на данные виды промышленных товаров практически на нулевом уровне. 
Значение Уругвайского раунда для Республики Корея определяется не только принятыми решениями как таковыми, но и тем фактом, что с этого момента торговая политика страны становится более диверсифицированной. Корейские власти стали последовательно вводить меры, адресно направленные на те или иные сектора экономики. Кроме того, Корея начала практиковать дифференцированный (с точки зрения набора обсуждаемых вопросов) подход к выстраиванию отношений с различными торговыми партнерами, вступать в коалиции как с развивающимися, так и с развитыми странами.

\section{Торговая политика Республики Корея как члена ВТО}

В первые годы после образования ВТО Республика Корея активно поддерживала многосторонний вариант либерализации торговли и сделала его важным направлением своей торговой политики. Может показаться, что соответствующий общей философии ВТО более открытый торговый режим шел вразрез с общей стратегической линией развития Кореи, которая и в 1990-е годы сохраняла целый ряд черт неомеркантилистского подхода. Следует особо отметить, что общественное мнение внутри страны было настроено против повышения уровня открытости национальных рынков и сельскохозяйственных, и промышленных товаров, считая, что это вредит национальным производителям. Вместе с тем многосторонняя либерализация включала определенный набор экономических выгод для страны в целом. Помимо этого, были и другие обстоятельства, позволившие корейскому правительству интегрировать меры по либерализации в торговую политику страны.

Во-первых, следует иметь в виду значительно окрепшие международные конкурентные позиции Кореи. Она превратилась из развивающейся в новую индустриальную страну. Если на момент начала Уругвайского раунда ВВП Республики Корея на душу населения составлял 5,5 тыс. долл., то в 1995 г. он увеличился более чем в 2 раза - до 11,9 тыс долл [54]. Это означало, что в своем развитии страна подошла к тому моменту, когда ведущие сектора экономики стали нуждаться в повышении уровня открытости для обеспечения новых источников роста. Действительно корейское промышленное лобби в период многосторонних переговоров Уругвайского раунда проявило себя весьма активно. Не в последнюю очередь под его влиянием власти согласились принять на себя обязательства, сопоставимые с развитыми странами, в отношении доступа на рынок несельскохозйственной продукции.

Во-вторых, в отличие от многих развивающихся стран к моменту образования ВТО Корея уже приложила немало усилий к реформированию своей торговой политики, готовясь к вступлению в ОЭСР. По оценке Р. Салли, «в силу того, что Республика Корея приняла ряд односторонних мер по либерализации, дальнейшее устранение барьеров в торговле в рамках международной системы представлялось для нее логическим продолжением процесса реформ» [43, р. 407]. 
Таким образом, можно сделать вывод, что к середине 1990-х годов внутренние условия, выразившиеся в достижении определенного уровня экономической зрелости, позволили корейскому правительству пойти по пути либерализации торговли. Обзоры ВТО по торговой политике страны отмечают значительный прогресс в области устранения торговых барьеров. Средний связанный уровень таможенного тарифа опустился на 10\% за 1996-2012 гг. (табл. 1). Число связанных тарифных линий составило 91,5\% (чуть ниже уровня 2012 г. по причине увеличения числа тарифных линий в международном классификаторе товаров) [64, p. 53]. В сельском хозяйстве Республика Корея связала $98,4 \%$ тарифных линий, в промышленности - 88,4\% [Ibid., p. 58].

\section{Таблииа 1}

Изменение таможенных тарифов в Республике Корея в 1996-2008 гт., \%

\begin{tabular}{|c|c|c|c|c|c|c|c|c|c|c|}
\hline \multirow{2}{*}{ Показатель } & \multicolumn{10}{|l|}{ Год } \\
\hline & \multicolumn{2}{|l|}{1996} & \multicolumn{2}{|l|}{2000} & \multicolumn{2}{|l|}{2004} & \multicolumn{2}{|l|}{2008} & \multicolumn{2}{|l|}{2012} \\
\hline $\begin{array}{l}\text { \% связанных тарифных } \\
\text { линий }\end{array}$ & \multicolumn{2}{|l|}{91,0} & \multicolumn{2}{|l|}{91,7} & \multicolumn{2}{|l|}{91,5} & \multicolumn{2}{|l|}{90,8} & \multicolumn{2}{|l|}{89,9} \\
\hline $\begin{array}{l}\text { Уровень тарифных } \\
\text { ставок }\end{array}$ & 1 & 2 & 1 & 2 & 1 & 2 & 1 & 2 & 1 & 2 \\
\hline Средний уровень для: & 27,6 & 14,4 & 20,2 & 13,8 & 17,2 & 12,8 & 17,1 & 12,8 & 17,6 & 13,3 \\
\hline $\begin{array}{l}\text { сельскохозяйственных } \\
\text { продуктов (HS01-24) }\end{array}$ & 72,4 & 51,8 & 65,5 & 50,3 & 61,1 & 47,9 & 61,7 & 47,8 & 63,4 & 55,0 \\
\hline $\begin{array}{l}\text { промышленных } \\
\text { товаров (HS25-97) }\end{array}$ & 20,0 & 7,7 & 12,8 & 7,5 & 10,0 & 6,6 & 9,8 & 6,5 & 9,2 & 6,6 \\
\hline текстиля и одежды & 28,5 & 7,8 & 23,1 & 9,8 & 18,5 & 9,8 & 18,4 & 9,7 & $16,5^{\star}$ & $9,0^{*}$ \\
\hline
\end{tabular}

Источник: WTO (2004) WT/TPR/S/137. P. 43-44; WTO (2008) WT/TPR/S/204/Rev. 1. P. 43-44; WTO (2012) WT/TPR/S/268. P. 58.

Вместе с тем определенные элементы защиты внутреннего рынка по-прежнему широко практикуются. Так, Корея продолжает сохранять одно из самых больших различий между уровнем таможенных ставок в промышленности и сельском хозяйстве. Например, средняя ставка таможенного тарифа для промышленных товаров равна $6,8 \%$, а для сельскохозяйственной продукции $-52,7 \%$ [65, p. 101]. Таким образом, разница между средним применяемым уровнем ставок составляет в Корее более $45 \%$, что в 4 раза выше, чем на Тайване, в 2,8 раза выше, чем в Японии, в 5 раз выше, чем в ЕС и почти в 21 раз выше, чем разница между ставками в США (табл. 2).

Столь существенный разрыв в ставках некоторые исследователи связывают с сохранившимися элементами неомеркантилистской ориентации предыдущих десятилетий [2, p. 110-11]. В Корее по причине опережающего развития промышленности и характерных географических условий сельское хозяйство было и остается более слабым не только относительно оте- 
чественной промышленности, но и по сравнению с аграрными секторами других государства. Данное обстоятельство обусловливает необходимость активной поддержки корейских производителей сельскохозяйственной продукции ${ }^{1}$, размер которой в 2013 г., по оценке ОЭСР, в процентном отношении составляет 52,5\%. Из стран - членов этой организации более высокий уровень поддержки в том же году имели Япония $(55,61 \%)$ и Норвегия $(52,86 \%)^{2}$. Необходимо отметить, что высокий уровень аграрного протекционизма в Корее является своего рода реакцией государства на позицию значительной части общества. Многие в стране придерживаются того мнения, что состояние корейского сельского хозяйства было бы значительно лучше без членства в $\mathrm{BTO}^{3}$.

Республика Корея активно использует и другие инструменты защиты интересов своих хозяйствующих субъектов, предоставляемые международной торговой системой. Так, механизм разрешения споров позволил стране поставить под сомнение правомерность некоторых ограничений, введенных в отношении корейских товаров рядом стран ${ }^{4}$. Еще одна возможность для защиты национальных производителей связана с разницей в уровнях связанных и применяемых ставок таможенного тарифа, иногда называемой «водой в тарифах». Данные, представленные в табл. 2, позволяют сделать вывод о том, что у Кореи этой «воды» существенно больше, чем у ее партнеров-конкурентов.

Стремление Кореи сохранять разрыв между ставками можно объяснить несколькими причинами. Первая связана с тем, что более высокий уровень связанных ставок будет служить базой для определения последующего плана снижений в случае успешного завершения Дохийского раунда переговоров. В данном случае либерализация тарифов будет осуществляться с более

1 Поддержка производителей (the Percentage Producer Support Estimate (\%PSE)) рассчитывается ОЭСР как сумма государственных трансфертов, полученная производителями сельскохозяйственной продукиии и выраженная как доля в общих денежных поступлениях производителей сельскохозяйственной продукции. Данный показатель оценивает поддержку, которую получают сельскохозяйственные производители в результате действия специальных мер, по сравнению с ситуачией, когда данные меры не применяются, т.е. производители оперируют в экономическом и налоговом режиме, являющейся общим для всех экономических агентов страны [36].

2 OECD <https://stats.oecd.org/Index.aspx?DataSetCode=MON20123_1\#>.

3 См., например: [30].

4 В одной из предшествующих работ авторы более подробно рассматривают данный аспект участия Республики Корея в ВТО. См.: [51]. 
высокого уровня и соответственно итоговая ставка окажется выше. Вторая причина связана с тем, что разрыв дает некую свободу в манипулировании применяемой ставкой. Правительство может, не нарушая взятых на себя обязательств, изменять ставку в пределах связанного уровня, чтобы защитить своих производителей в кризисные периоды [64, p. 58].

Помимо указанных преимуществ наличие разрыва создает для Республики Корея определенные преимущества в переговорном процессе вне рамок BTO. Например, при обсуждении ССТ корейское правительство может пойти на большие уступки по ставкам, чтобы существенно улучшить условия доступа на рынок страны, с которой ведутся переговоры. В целом анализ корейских ССТ подтверждает данный тезис. Применяемые ставки тарифов в рамках преференциальных соглашений ощутимо ниже [47, p. 4].

\section{Таблица 2}

Связанные и применяемые ставки импортных пошлин в отдельных странах - членах ВТО, \%, 2013 г.

\begin{tabular}{|c|c|c|c|c|c|c|c|c|c|c|}
\hline & \multicolumn{2}{|c|}{$\begin{array}{l}\text { Республика } \\
\text { Корея }\end{array}$} & \multicolumn{2}{|c|}{ Тайвань } & \multicolumn{2}{|c|}{ Япония } & \multicolumn{2}{|l|}{ EC } & \multicolumn{2}{|c|}{ США } \\
\hline $\begin{array}{l}\text { \% связанных тарифных } \\
\text { линий }\end{array}$ & \multicolumn{2}{|l|}{94,6} & \multicolumn{2}{|l|}{100} & \multicolumn{2}{|l|}{99,6} & \multicolumn{2}{|l|}{100} & \multicolumn{2}{|l|}{100} \\
\hline Среднее для: & 1 & 2 & 1 & 2 & 1 & 2 & 1 & 2 & 1 & 2 \\
\hline $\begin{array}{l}\text { всех категорий } \\
\text { товаров }\end{array}$ & 16,6 & 13,3 & 6,3 & 6,1 & 4,7 & 4,9 & 5,2 & 5,5 & 3,5 & 3,4 \\
\hline $\begin{array}{l}\text { сельскохозяйственных } \\
\text { товаров }\end{array}$ & 56,0 & 52,7 & 16,9 & 16,0 & 19,0 & 19,0 & 13,5 & 13,2 & 4,9 & 5,3 \\
\hline $\begin{array}{l}\text { промышленных } \\
\text { товаров }\end{array}$ & 10,2 & 6,8 & 4,7 & 4,5 & 2,5 & 2,6 & 3,9 & 4,2 & 3,3 & 3,1 \\
\hline
\end{tabular}

Примечание. 1 - средний связанный уровень ставки; 2 - средний связанный уровень режима наибольшего благоприятствования.

Источник: [31].

Корейская позиция относительно повестки Дохийского раунда переговоров также в немалой степени определяется стремлением защитить национальных производителей, и в первую очередь, производителей сельскохозяйственной продукции. Максимизировать защиту Корея сможет в том случае, если удастся сохранить за собой статус развивающейся страны. В случае успеха Корея получит более длительные сроки либерализации данного сектора: десять лет вместо пяти [61]. Для того чтобы усилить свои переговорные позиция, Корея присоединилась к ряду коалиций, сформировавшихся в ходе переговоров Доха-раунда. Одна из коалиций - так называемая «группа десяти» (G10), активно выступающая за более высокий уровень защиты в сельском хозяйстве по причине его значимости для культуры, продовольственной самообеспеченности и проч. Другая коалиция, в которой Корея довольно активна, - «группа 33» (G33), также носящая название «Друзья специальных товаров». Данная группа сфоку- 
сирована на то, чтобы добиться для развивающихся стран более мягких условий либерализации.

В 1990-е годы статус развивающейся страны важен для Кореи и в части более выгодных условий либерализации сектора услуг. В отличие от сельского хозяйства, которое в целом характеризуется относительно низкой степенью конкурентоспособности, корейский сектор услуг неоднороден: конкурентоспособные отрасли сосуществуют с менее развитыми. К последним относятся почтовые, аудио- и авиауслуги, услуги в сфере образования [64, p. 136]. В числе первых - морские перевозки, строительство, мобильные коммуникации, а также финансовые услуги. За прошедшее время данные сектора смогли значительно укрепить свои международные позиции. Более того, в соответствии с действующей концепцией развития страны они рассматриваются в качестве возможных «двигателей роста». В результате в отличие от первоначального стремления отсрочить их либерализацию, корейские власти стали выступать за обеспечение большей открытости для данных видов услуг и пытаются стимулировать их дальнейшей развитие, включая интернационализацию как неотъемлемый компонент развития [69, p. 45-63].

Таким образом, и в случае участия в коалициях в рамках ВТО Корея стремится дифференцировать свою торговую политику. Она поддерживает развивающиеся страны в вопросах торговли сельскохозяйственной продукцией, а развитые - в вопросах доступа на рынок услуг. Более того, несбалансированное развитие отраслей национальной экономики дает Корее основание стремиться играть роль активного посредника между развитыми и развивающимися государствами.

Вместе с тем постепенно общий уровень интереса и ожиданий Республики Корея, связанных с участием в работе ВТО, начинает снижаться. В начале 2000-х годов страна стала в большей степени ориентироваться на заключение преференциальных торговых соглашений, тогда как вопросы многосторонней либерализации утратили свой приоритет $[27 ; 19]$.

1 Закон о промьиитенном развитии от 23 марта 2013 г. № 11690 //산업 발전 법 [Law on industrial development]. URL: $<$ http://www.law.go.kr/lsInfoP.do?lsiSeq $=136954 \# 0000>$. Кроме того, в настоящий момент (май 2015 г.) в Парламенте Республики Корея проходит обсуждение закона о развитии сектора услуг, предусматривающего более высокую степень либерализации отрасли. Отметим, ито обсуждение данного проекта закона протекает весьма сложно, и перспективы его скорого принятия пока неясны // 서비스발전·관광진흥법 등 6개 무산 $\cdots$ 6월 국회 처리도 불투 명. 한국일보2015.05.07 04:40 [Prospects remain unclear about passing of law on service sector development and law for promotion of tourism industry in June]. URL: $<$ http://www. hankookilbo.com/v/a151e49be0c14ddcadedf7cf54f750ba>. 


\section{Торговая политика Кореи в 2000-е годы: акцент на регионализацию}

Многосторонняя либерализация, несмотря на ее положительное воздействие на процесс экономического развития Республики Корея, в целом не нашла широкого отклика в корейском обществе. Переход к политике заключения региональных торговых соглашений был в значительной мере спровоцирован кризисом 1997-1998 гг., охватившим большинство стран Восточной и Юго-Восточной Азии и заставившим их искать пути решения общих для них проблем. Последние были во многом связаны с реализацией практически всеми государствами региона экспортно ориентированной модели развития, теоретической основой которой была концепция (парадигма «летящих гусей» ${ }^{1}$ [23]. Возможности экстенсивного роста за счет увеличения объемов вводимых в оборот ресурсов [29] в условиях порождаемого стремлением к снижению издержек дробления производственных процессов столкнулись с серьезными ограничениями. Региональные торговые соглашения в складывающейся ситуации открывали новые перспективы расширения экспортных поставок [25]. При этом регионализация позволяла добиться желаемого эффекта, одновременно сохраняя в силе отдельные механизмы защиты внутреннего рынка.

Власти Республики Корея напрямую связывали с ССТ повышение национальной конкурентоспособности. Корейские исследователи отмечают, что «президент Но [Му Хен] рассматривал ССТ в качестве стратегического инструмента для отстаивания интересов Кореи в новой геополитической и геоэкономической среде» [46, p. 444-449]. Посредством межрегиональных соглашений с США и ЕС, которые были заключены страной во второй половине 2000-х годов, Корея способствовала усилению конкуренции между странами Восточной Азии в области политики по заключению ССТ [9].

Инициатива правительства по усилению регионального компонента в торговой политике страны была горячо поддержана бизнесом, усилившиеся международные конкурентные позиции которого позволяли делать ставку на ССТ [39, p. 8-9; 38, р. 32-34; 40, p. 82]. В принципе корейские компании постоянно ощущали потребность преодолевать ограниченность национального рынка. В отличие от Японии с населением свыше 130 млн человек

1 Данная кониепиия (парадигма) была разработана в конце 1930-х годов японским ученым К. Акамачу. По его мнению, существует три фбазы развития отрасли: фаза 1 - продукиия поступает в экономику через импорт зарубенных производителей; база 2 - для удовлетворения растущего национального спроса открываются новые местнье производства; фаза 3 - излишки продукиии экспортируются на новые зарубежные рьнки. Акамачу полагал, что последовательное появление импорта (M), местного производства (P) и экспорта (X) графически напоминают формирование стаи диких гусей. 
и, как следствие, достаточно емким внутренним рынком, 50 млн человек, живущих в Корее, не в состоянии обеспечить устойчивую платформу для роста, что ставит развитие страны в намного большую, чем в случае страны восходящего солнца, зависимость от внешнеторговой экспансии.

Отдельно необходимо обратить внимание на то, что переориентация на региональные торговые соглашения была напрямую сопряжена с нарастающим разочарованием в перспективах многосторонней торговой либерализации. Первоначальным надеждам на быстрое успешное выполнение весьма амбициозных планов, зафиксированных в декларации Министерской конференции ВТО 2001 г., не суждено было сбыться. Большинство специалистов сходятся во мнении, что выбор в пользу ССТ в условиях отсутствия прогресса на переговорах Дохийского раунда представляется вполне логичным, если не неизбежным [66, р. 193-212; 10, p. 129].

В свою очередь, активность Кореи по заключению ССТ поставила под сомнение приверженность страны принципам многосторонней либерализации и готовность прикладывать усилия для успешного завершения Дохийского раунда [44]. Один из главных корейских специалистов по торговой политике Ку признает, что «рост активности Кореи по заключению преференциальных торговых соглашений привел к снижению интереса к многостороннему формату, которому страна традиционно следовала» [26].

Необходимо отметить, что росту интереса к региональным формам либерализации со стороны Кореи, равно как и других стран региона, способствовало развитие интеграционных процессов в Европе и в западном полушарии $[25$, р. 5]. Ни в коей мере не идеализируя эти процессы, азиатские государства положительно оценивали потенциал регионализации в вопросах повышения мобильности факторов производства, минимизации транзакционных издержек и временных потерь и в конечном счете в улучшении показателей экономической эффективности [67, p. 22]. В дополнение к вышеперечисленному, корейский исследователь Ку указывает на такое важное преимущество ССТ, как большее равенство партнеров в переговорном процессе: «в отличие от традиционного многостороннего механизма ГАТТ/ ВТО ССТ между партнерами с неравными либо асимметричными переговорными позициями снижает риск того, что один из партнеров “проедет зайцем” за счет другого» [27, p. 106]. Наконец, по мнению корейского исследователя Чоя, региональный подход к вопросам торговли рассматривался Кореей с точки зрения частичного разрешения проблем стратегической безопасности $[8$, p. 1$]$.

Первые шаги Республики Корея в заключении ССТ были весьма осторожны, предпочтение отдавалось тем партнерам, международная специализация которых значительно отличалась от специализации Кореи и для которых торговля сельскохозяйственной продукцией не являлась принципиальным вопросом переговорной повестки. В соответствии с данным подходом выбор 
был сделан в пользу Чили ${ }^{1}$, Сингапура и Европейской ассоциации свободной торговли (ЕАСТ). Несмотря на то что эффект в корейской экономике от данных соглашений в целом был невысок, они имели большое значение для корейских властей. Речь, в частности, идет о возможности постепенного осмысления на основе накопленного опыта негативных последствий для национальной экономики, приобретения навыков ведения переговоров и решения возникающих в его ходе проблем. В результате Корея достаточно хорошо подготовилась к намного более сложным и значимым для нее переговорам с такими важными торговыми партнерами, как США и ЕС.

В 2003 г. администрация президента Но Му Хена составила дорожную карту по заключению ССТ. К тому моменту первоначальная идея региональной либерализации, направленной на «создание связей между отечественной промышленностью и внешними рынками посредством ССТ» [66, p. 206], трансформировалась в план превращения Сеула в так называемый «хаб» ССТ. Это подразумевало, что Корея будет выступать в качестве связующего звена между странами, территориально находящимися в разных регионах. Здесь можно усмотреть некие параллели с позицией Кореи в ВТО, где она, как отмечалось, стремится быть посредником в переговорах между развитыми и развивающимися странами.

Однако дать оценку тому, насколько успешно прошла реализация данных инициатив, довольно сложно. Тем не менее необходимо отметить, что на сегодняшний день Корея - страна, заключившая наибольшее количество соглашений. При этом только она заключила ССТ сразу с тремя крупнейшими участниками мирохозяйственной системы - США, ЕС и Китаем. По состоянию на март 2015 г. ею ратифицировано 11 соглашений, подписано 5, в процессе согласования находилось еще 3. Помимо этого, началась подготовка к переговорному процессу с тремя странами, а также сформированы рабочие группы для исследования возможностей заключения ССТ с еще четырьмя государствами. Положение в «эпицентре» межрегиональных торговых связей позволило Республике Корея усилить свое международное влияние, претендовать на положение лидера в развитии интеграционных процессов в Восточной Азии, которое ранее занимали Япония и страны Юго-Восточной Азии.

Одно из последних соглашений Республики Корея было подписано в декабре 2014 г. с Китаем. Оно стоит в ряду важнейших экономических достижение действующего президента Пак Гын Хе. Ожидается, что после ратификации данное соглашение позволит Корее к 2023 г. довести долю торгового

1 Из числа первых соглашений именно ССТ с Чили, ратифицированное в 2004 г., считается наиболее удачным, поскольку оно позволило значительно увеличить объемы двусторонней торговли [67, р. 60-68, 92-95]. 
оборота, осуществляемую внутри ССТ, с 35 до 80\%ํ. Вместе с тем сложилось положение, при котором ССТ охвачены все основные торговые партнеры Кореи. Означает ли это, что для страны потенциал регионального формата либерализации, по существу, исчерпан? Как в связи с этим может трансформироваться корейская торговая политика?

\section{Приоритеты на будущее: региональная или многосторонняя либерализация?}

Региональный компонент в торговой политике Кореи, как отмечалось, направлен на достижение комфортных для Кореи условий либерализации при сохранении достаточно высокого уровня защиты в сельском хозяйстве и других уязвимых отраслях национальной экономики. По этой причине многие ученые указывают на протекционистский характер корейских ССТ [3]. В отличие от правил ВТО, не позволяющих странам делать множественные исключения секторов из итоговых обязательств, региональные соглашения (несмотря на содержащееся в ст. XXIV ГАТT требование распространения преференциального режима на «практически всю торговлю») предоставляют в этом отношении намного больше возможностей. Наглядным подтверждением сказанного является довольно низкий уровень беспошлинных тарифных линий в ССТ, заключенных Кореей [WTO 2012, p. 59-60]. Так, большое число сельскохозяйственных товаров исключено из договорных обязательств Кореи в рамках ССТ с Сингапуром (33,3\%), ЕАСТ (65,8\%), АСЕАН (30,9\%), Чили (29\%), КНР $(36 \%)^{2}$ [47, р. 6]. В последнем случае Корея, опасаясь конкуренции со стороны китайских производителей, вывела из-под либерализации целый ряд промышленных товаров. Таким образом, корейские ССТ оказывают ограниченное воздействие на уровень либерализации внутреннего рынка, а их влияние на трансформацию национального хозяйства не столь велико [3]. Следует отметить, что, по мнению Ку, акцент на регионализацию негативно отразился на общем уровне либерализации корейской торговли в рамках ССТ по сравнению с уровнем обязательств Кореи в ВТО [26].

Подобная «ограниченная» либерализация ставит ряд вопросов относительно возможностей для повышения посредством ССТ эффективности националь-

1 韓 FTA 무역비중, 10 년 새 $35 \% \rightarrow 85 \%$ 확대 전망 [Korean trade within FTA is projected to in-crease from 35\% to 85\% within next 10 years] // Newsis 2013.14.06. URL: $<$ http://www.newsis.com/article/view.htm? $c I D=\mho \sim a r \_i d=N I S X 20130613 \_0012158304>$.

2 К ним относятся рис, говядина, свинина, мясо курицы и утки, яблоки, груши, виноград, иитрусовые, красный переи, чеснок и лук // Im, Jeongbin. 2014. Impacts of Korea-China FTA on the Korean agriculture. URL: <http://ap.fftc.agnet.org/ ap_db.php?id=353>. 
ной экономики. В низкоконкурентной среде, которая формируется в результате множественных изъятий, корейские компании не имеют достаточных стимулов для поиска новых возможностей оптимизации производства. Ранее экономический эффект от заключения преференциальных соглашений для промышленности достигался за счет увеличения числа новых соглашений, что позволяло количественно наращивать объемы экспорта, сохраняя общую стратегию ведения бизнеса. Однако с сокращением возможностей для заключения новых соглашений наращивать экспорт за счет экстенсивных факторов будет сложнее. В этих условиях добиться увеличения экспорта и повышения эффективности можно либо в рамках многосторонней либерализации, либо посредством ССТ, предполагающих более комплексную либерализацию.

Осознавая указанные ограничения, корейские власти снова начали проявлять больший интерес к многосторонней повестке в рамках ВТО. Президент Ли Мен Бак (2008-2012) поддержал инициативу скорейшего завершения Дохийского раунда, о чем свидетельствует включение данного вопроса в повестку саммита Большой двадцатки в Сеуле в 2010 г. ${ }^{1}$ Действующий президент Пак Кын Хе в своей речи на саммите АТЭС в 2013 г. также отметила важность «процветания многосторонней торговой системы» [37]. Можно предположить, что такое поведение корейских лидеров основано на предположениях о тех выгодах, которые может предоставлять многосторонняя либерализация для развития страны. Кроме того, существуют объективные обстоятельства, которые заставили корейское руководство вновь обратиться к деятельности ВТО и могут оказывать влияние на выбор общего направления торговой политики.

Во-первых, корейский бизнес весьма озабочен своими позициями в мировой торговле, сегодня характеризующейся высокой степенью географической фрагментации. Глобальные производственные системы изменили подходы к тому, что́ означает быть вовлеченным в мировую торговлю. Корейские фирмы, как и другие вертикально-интегрированные компании, вынуждены контролировать большой спектр операций, осуществляемых в разных регионах мира [50, p. 4]. Подобная структура бизнеса требует высокого уровня координации производства и торговли внутри компании, оптимизации всей ее деятельности ${ }^{2}$. Принимая во внимания тот факт, что общий уровень тариф-

1 Итоговая деклараиия тидеров стран Большой двадиатки, принятая на саммите в Сеуле. The G20 Seoul Summit Leaders' Declaration, 2010. 11-12 nov. URL: $<$ http://www.iccwbo.org/Advocacy-Codes-and-Rules/BASCAP/International-engagementand-Advocacy/G20-Seoul/>.

2 Вертикальная специализация предполагает высшую степень интенсивности транспортных операций. Товары пересекают границы много раз, поэтому даже небольшие транспортные издержки и торговые споры имеют тендениию накапливаться и давать большой экономический эфбект [55, p. 3]. 
ных барьеров в мире уже находится на довольно низком уровне, дальнейшая оптимизации возможна в случае разрешения таких вопросов, как содействие торговле, прозрачность и проч., являющихся частью повестки ВТО.

Во-вторых, вызывает сомнения, что ССТ могут обеспечить надлежащий уровень регулирования всей совокупности операций корейских глобальных компаний. Для этого ВТО обладает существенно большими возможностями. В ВТО заложен потенциал превратиться в «наиболее эффективную и влиятельную экономическую организацию» [42, р. 3], чего нельзя сказать о преференциальных соглашениях, ограничивающих достигнутый эффект только странами, их подписавшими.

В-третьих, в 2016 г. согласно взятым на себя обязательствам в ВТО, Республика Корея должна установить тарифы на импорт риса вместо действующей системы квотирования. Социальная значимость данного вопроса заставляет корейские власти искать пути снятия напряженности в обществе, которая может возникнуть. Поэтому в настоящий момент они уделяют больше внимания вопросам многосторонней либерализации.

Необходимо отметить, что Корея пока не дала официального согласия на участие в транстихоокеанском партнерстве, предложенном США. Корея медлит с ответом, объясняя это тем, что у нее уже есть ССТ с США, и она сможет присоединиться в любой момент позднее. Однако позицию Кореи можно объяснить и опасениями относительно перспектив открытия национального рынка для конкурентоспособных товаров японской промышленности ${ }^{1}$.

\section{Заключение}

В формировании и проведении своей торговой политики Республика Корея стремилась сочетать два формата либерализации - многосторонний и региональный. При этом, несмотря на то что в определенные моменты времени происходило относительное усиление или ослабление одного либо другого компонента, цель оставалась неизменной - максимизировать выгоды от торговли для повышения уровня национального благосостояния. Так, членство в ВТО позволило Корее находиться в русле мировых тенденций развития торговли, стать неотъемлемой частью глобальных производственных систем, увеличить объемы экспорта, что было особенно важно в первые десятилетия экономического развития страны. ССТ в более поздние годы способствовали количественному наращиванию экспорта и тем самым росту экономики в условиях, когда

1 최병일. TPP, 강 건너 불이 아니다 [TPP is not 'fire on other bank of the // 동아일보201504-28. URL: <http://news.donga.com/3/all/20150428/70947262/1>. 
международная торговая система не позволяла это достичь. Акцент на регионализацию позволял корейскому правительству обеспечивать должный баланс между уровнем внешнеторговой открытости и степенью защищенности национального рынка.

Торговая политика Республики Корея предполагала дифференцированный подход к обсуждению вопросов различной степени сложности в зависимости от уровня развития торгового партнера. Именно по этой причине ССТ, ею заключенные, весьма неоднородны по своему содержанию и уровню либерализации. Обширная повестка соглашений с ЕС и США сочетается с множественными исключениями в соглашениях с ЕФТА, Сингапуром и Китаем.

В настоящее время Республика Корея должна решать вопрос о присоединении к активно лоббируемому Соединенными Штатами транстихоокеанскому партнерству. В случае принятия положительного решения корейская торговая политика, скорее всего, пойдет по пути дальнейшего усиления компонента региональной либерализации. В случае же отказа весьма вероятно перенесение акцента на многосторонний формат. В пользу данного варианта говорит и то, что на современном этапе развития именно многосторонняя система может открыть Корее новые возможности и перспективы.

\section{Литература}

[1] Dukgeung Ahn. GATT/WTO dispute dettlement and Korea: from passivity to aggression // CDAMS Discussion paper. 2004. 04/3E.

[2] Amsden A., Hikino T. The bark is worse than the bite: new WTO law and late industrialization // Annals of American Political and Social Science. 2000. Vol. 570 (July). P. 104-114.

[3] Armstrong Sh. Korea: beyond preferential trade deals // Korea's Economy. 2012. Korea Economic Institute of America. URL: <http://keia.org/category/ publication-category/koreas-economy/koreas-economy-2012>. P. 35-41.

[4] Bagwell K., Staiger R.W. An economic theory of GATT // American Economic Review. 1999. Vol. 89. P. 215-248.

[5] Bhagwati J. US trade policy: The infatuation with FTAs. Discussion Paper Series. 1995. Columbia University. No. 72.

[6] Brown D.K., Deardorff A.V., Stern R.M. Multilateral, regional and bilateral trade-policy options for the United States and Japan // World Economy. 2003. Vol. 26. No. 6. P. 803-828. 
[7] Busch M.L., Mansfield E.D. The political economy of trade policy // Denemark R.A. et al. (eds). The international studies compendium project. Oxford: Wiley-Blackwell, 2011.

[8] Choi Y.J. East Asian regionalism and South korea's strategy: Lessons from the experience of middle power activism. 2004. URL: <http://www.jpi.or.kr/ board/run/download.php?board_id=peaceindustry\&page=1\&row_per_ page $=15 \&$ page_per_block=10\&pds_uid $=1304>$.

[9] Corning G.P. Trade regionalism in a realist East Asia: Rival visions and competitive bilateralism // Asian Perspective. 2011. Vol. 35. No. 2 (AprilJune). P. 259-286.

[10] Deese D.A. World trade politics: Power, principles, and leadership. L.: Routledge, 2008.

[11] Dent Ch. Free trade agreements in the Asia-Pacific: A risky game being played at the wrong time. Evian Group Policy Brief. 2006. April. URL: <http://www. imd.org/uupload/EvianGroup/PUBLICATIONS/1236.pdf>.

[12] Feenstra R., Hamilton G. Emergent economies, divergent paths: economic organization and international trade in South Korea and Taiwan. N.Y.: Cambridge University Press, 2006.

[13] Frankel J., Romer D. Does trade cause growth? // American Economic Review. 1999. Vol. 89. No. 3. P. 379-399.

[14] Gawanade K., Krishna P., Olarreaga M. What governments maximize and why: The view from trade // International Organization. 2009. Vol. 63. Iss. 03. July. P. 491-532. URL: <http://dx.doi.org/10.1017/ S0020818309090171>.

[15] Grossman G.M., Helpman E. Trade wars and trade talks // Journal of Political Economy. 1995. Vol. 103. P. 675-708.

[16] Hamilton G., Feenstra R., Petrovic M. The emergence of demand-responsive economies: A reassessment of the 'Asian Miracle' (mimeo). Wash.: University of Washington, 2003.

[17] Holmes P., Hoekman B. Competition policy, developing countries and the WTO. World Bank. Wash., 2004.

[18] Humphrey J. Upgrading in global value chains. Working Paper. 2004. No. 28.

[19] Hwang Doo-yun. Korea's international trade policy in the global age // East Asian Review. 2001. Vol. 13. No. 3. P. 3-20. 
[20] Irwin D.A. Welfare effects of British Free trade: Debate and evidence from the 1840's // Journal of Political Economy. 1988. Vol. 96. No. 6. P. 1142-1164.

[21] Irwin D. The rise of US antidumping actions in historical perspective. NBER Working Paper. 2004. No. 10582. URL: <http://www.nber.org/papers/w10582>.

[22] Johnson H.G. Optimum tariffs and retaliation // The Review of Economic Studies. 1954. Vol. 21. P. 142-153.

[23] Kasahara S. The Asian development state and the flying geese paradigm. UNCTAD discussion papers. 2013. No. 213. URL: <http://unctad.org/en/ PublicationsLibrary/osgdp20133_en.pdf $>$.

[24] Kawai M. East Asian economic regionalism:progress and challenges// Journal of Asian Economics. 2005. Vol. 16. P. 29-55.

[25] Kawai M., Wignaraja G. The Asian 'Noodle Bowl': Is it serious for business? ADBI Working Paper Series. 2009. Vol. 136. April. URL: <http://www.adbi. org/files/2009.04.14.wp136.asian.noodle.bowl.serious.business.pdf>.

[26] Koo Min Gyo. South Korea's FTAs: moving from an emulative to a competitive strategy. Conference paper, the International Symposium 'Competitive Regionalism', Ibuka International Conference Hall. Tokyo, Japan: Waseda University, 30-31 May 2008.

[27] Koo Min Gyo. Embracing Free Trade Agreements, korean style: From developmental mercantilism to developmental liberalism // The Korean Journal of Policy Studies. 2010. Vol. 25. No. 3. P. 101-123.

[28] Korea to open service sectors under WTO DDA format // Korea.net, 25 May 2005. URL: <http://www.korea.net/news/news/NewsView. asp?serial_no $=20050524017 \&$ part $=109 \&$ SearchDay $=>$.

[29] Korgun I., Popova L. Role of foreign economic factors in Korea's economic development. S.-Pt.: Saint-Petersburg State University Publishing House, 2011.

[30] Lee Y.K., Kim H. Korean agriculture after the Uruguay round and world agricultural policy reform. [Conference paper] The International Conference 'Agricultural policy reform and the WTO: where are we heading?' Capri (Italy) 23-26 June. URL: <http://www.ecostat.unical.it/2003agtradeconf/ Contributed\%20papers/Lee\%20and\%20Kim.pdf $>$.

[31] Lee You-il, Lee Kyung Tae. Economic nationalism and globalisation in South Korea: A critical insight // Asian Perspective. 2015. Vol. 39. No. 1 (JanuaryMarch). P. 125-151. 
[32] Lee Y.S. The beginning of economic integration between East Asia and North America? // Buckley R., Lo V.I., Boulle L. (eds). Challenges to Multilateral Trade: The impact of Bilateral, preferential and regional agreements. Netherland: Kluwer Law International, 2008. P. 125-160.

[33] Lejárraga I. Multilateralising regionalism: Strengthening transparency disciplines in trade // OECD Trade Policy Papers. 2013. No. 152. URL: <http:// dx.doi.org/10.1787/5k44t7k99xzq-en>.

[34] Lloyd P. New bilateralism in the Asia Pacific // World Economy. 2002. Vol. 25. No. 9. P. 1279-1296.

[35] Nakatomi M. Global Value Chain' in East Asia. Presentation for the launch of the WTO and IDE-JETRO publication Trade Patterns and Global Value Chains in East Asia, 2011. URL: <http://www.wto.org/english/news_e/ news11_e/miwi_06june11_nakatomi_e.ppt $>$.

[36] URL: <http://www.oecd.org/tad/agricultural-policies/producerandconsume rsupportestimatesdatabase.htm>.

[37] Park Geun-Hye. Speech at APEC Leader's Meeting in Indonesia. 2013. 8 October.URL:<http://www.mofa.go.kr/webmodule/htsboard/template/read/engreadboard.jsp?typeID $=12 \&$ boardid $=14195 \&$ seqno $=312896 \& \mathrm{c}=\& \mathrm{t}=\&$ pagenum $=1 \& \mathrm{t}$ ableName $=$ TYPE_ENGLISH $\& p c=\& d c=\& w c=\& l u=\& v u=\& i u=\& d u=>$.

[38] Park S.-H., Koo M.G. Forming A Cross-Regional Partnership: The South Korea-Chile FTA And Its Implications // Katada S.N., Solis M. (eds). Cross Regional Trade Agreements: Understanding Permeated Regionalism in East Asia. N.Y.: Springer, 2008. P. 27-46.

[39] Park Y.B., Moon S.B. Korea's FTA policy structure. Conference paper, the AKSE Conference 'Korea and the World Economy'. 2006. 7-8 July, Korea University (Seoul).

[40] Rhyu S.Y. South Korea's political dynamics of regionalism: A comparative study of Korea-Japan FTA and Korea-U.S. FTA // Aggarwal V.K., Lee Seungjoo (eds). Trade policy in the Asia-Pacific: The role of ideas, interests and domestic institutions. N.Y.: Springer, 2011. P. 71-87.

[41] Rodrik $D$. The global governance of trade as if development really mattered. Report submitted to the UNDP. 2001. URL: <http://www.giszpenc.com/ globalciv/rodrik1.pdf>.

[42] Ruggiero $R$. The future path of the multilateral trading system. WTO Director-General's address to the Korean Business Association. 17 April. URL: <http://www.wto.org/english/news_e/pres97_e/seoul.htm>. 
[43] Sally R. Developing country trade policy reform and the WTO // Cato Journal. 2000. Vol. 19. No. 3. URL: <http://object.cato.org/sites/cato.org/ files/serials/files/cato-journal/2000/1/cj19n3-8.pdf>.

[44] Schott J.J. The Doha dilemma: Implications for Korea and the Multilateral Trading System. Conference paper, the KITA-PIIE International Conference, 2011. 26 September, South Korea.

[45] Schott J.J., Cimino C. Should Korea Join the Trans-Pacific Partnership? Peterson Institute for International Economics, Policy Brief PB 2014. 14-22 September.

[46] Sohn Y., Koo M.G. Securitizing trade: The case of the Korea-US free trade agreement // International Relations of the Asia-Pacific. 2011. No. 11. P. $433-460$.

[47] SolÍs M. South Korea'sfatefuldecision on the Trans-PacificPartnership// Policy Paper. 2013. No. 31 (September). Wash.: Brookings Institute.

[48] Srinivasan T.N., Bhagwati J. Outward orientation and development: Are the revisionists right? // Economic growth center, Yale University Center. Discussion Paper No. 806. 2001. URL: <http://www.econ.yale.edu/growth_ pdf/cdp806.pdf $>$.

[49] Stern J. et al. Industrialization and the State: The Korean heavy and chemical industry drive (Harvard Studies in International Development). Harvard: Harvard University Press, 1995.

[50] Sturgeon T., Lee J.-R. Industry co-evolution and the rise of a shared supplybase for electronics manufacturing // Massachusetts Institute of Technology Working Paper Series. 2001. MIT-IPC-01-003.

[51] Sutyrin S. International Trading System - Does it really represent a public good? // World Journal of Management \& Economics. 2007. No. 2 (2). URL: $<$ http://worldec.ru/content/articles/WJMEC-Volume_2_Issue_1.pdf $>$.

[52] Sutyrin S. Regional and global in the inter-civilizational cooperation // SaintPetersburg State University Journal (Economics Series 5). 2006. No. 1. P. 55-63.

[53] Sutyrin S., Korgun I. Korea in the International Trading System. SaintPetersburg, 2008 (In Russian).

[54] URL: <http://unctadstat.unctad.org/wds/ReportFolders/reportFolders.aspx>.

[55] Venables A.J. Vertical specialization. Unpublished mimeo. Geneva: ILO, 2002. 


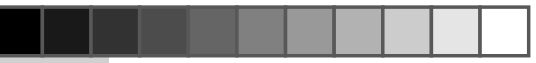

[56] Winters L.A. Trade policy as development policy: Building on fifty years' experience. UNCTAD Round Table report 1999. URL: <http://www.unctad. org/en/docs/ux_tdxrt1d2.en.pdf>.

[57] WTO. World Trade Report. The WTO and preferential trade agreement: from co-existence to coherence. Geneva, 2011.

[58] WTO. Trade Policy Review of the Republic of Korea. WT/TPR/S/19. 1996.

[59] WTO. Trade Policy Review of the Republic of Korea. WT/TPR/S/137. 2004.

[60] WTO. Trade Policy Review of the Republic of Korea. WT/TPR/S/204/Rev.1. 2008a.

[61] WTO. Unofficial guide to the revised draft modalities - agriculture, December 6. 2008b. URL: <http://www.wto.org/english/tratop_e/agric_e/ ag_modals_dec08_e.htm>.

[62] WTO. WT/MIN(09)/ST/14. 2009a. December 1.

[63] WTO. WT/MIN(11)/ST/21. 2009b. December 16.

[64] WTO. Trade Policy Review of the Republic of Korea. WT/TPR/S/268. 2012.

[65] WTO. Trade Profiles 2014.

[66] Yoshimatsu H. Political Leaders' Preferences and Trade Policy: Comparing FTA Politics in Japan and South Korea, Asian Politics \& Policy. 2012. No. 4 (2). P. 193-212.

[67] Bae C.K., Kim J.G., Kum H.Y., Chang Y.J. 한국 기발효 FTA의 경제적 효과 분석 [Analysis of Economic Effect of Korea’s FTAs] // KIEP Reasearch Paper. 2012. No. 12-03.

[68] Lee J. H. 농업 문제에 대한 몇 가지 오해 [Several common mistakes about agriculture] // Korean Economy Magazine. 2014. Vol. 946.13 January. URL: $<$ http://magazine.hankyung.com/business/apps/s?popup=0\&nid=01\&c1=1 $002 \&$ nkey $=2014011600946000351 \&$ mode $=$ sub_view $>$.

[69] Song Y.K. 서비스 협상 전망 및 대응방안 [Agreement on services and perspectives for Korea] // DDA 협상 전망 및 분야별 대응방안DDA hyeopssang jeonmang mit bunyabyeol daeeungbangan [DDA and Korea's response to negotiations]. Seoul. 2008. P. 45-63. URL: <http://www.prism.go.kr/ homepage/researchCommon/retrieveResearchDetailPopup.do;jsessionid=27732 6EDBEF1C7790C1657B4F97E9B8E.node02?research_id=1260000-200800033 >.

[70] 산업 발전법 [Law on industrial development] URL: <http://www.law.go.kr/ lsInfoP.do?lsiSeq=136954\#0000>. 
[71] 서비스발전·관광진흥법 등 6개 무산... 6월 국회 처리도 불투명. 한국일보2015.05.07 04:40 [Prospects remain unclear about passing of law on service sector development and law for promotion of tourism industry in June]. Available at: <http://www.hankookilbo.com/v/a151e49be0c14ddcade df7cf54f750ba>.

[72] 최병일. TPP, 강 건너 불이 아니다 [TPP is not 'fire on other bank of the river // 동아일보2015-04-28. URL: <http://news.donga.com/3/ all/20150428/70947262/1>.

[73] 韓 FTA무역비중, 10 년 새 $35 \% \rightarrow 85 \%$ 확대 전망 [Korean trade within FTA is projected to increase from $35 \%$ to $85 \%$ within next 10 years] // Newsis 2013-06-14. URL: <http://www.newsis.com/article/view.htm?cID=\&ar_ id=NISX20130613_0012158304>.

Sutyrin S., Korgun I. ${ }^{1}$

\section{Trade policy of the Republic of Korea: searching for the balance between regional and multilateral liberalisation}

This research deals with some of the issues relating to Korea's trade policy. Authors focus on how GATT participation aided Korean development in the early stages of growth and reasons why the government turned to FTA policy in 2000's. The paper argues that current domestic and international environment opens new opportunities for Korea to maximize economic benefits through wider engagement in the multilateral trading system, therefore it is ready to play a more active role in various arrangements and pledged its commitment for Doha round completion. However, prospects that regional dimension of Korea's trade policy will deepen cannot be abolished fully since government might decide positively on TPP participation.

Key words: trade policy, WTO, free trade agreements, Republic of Korea.

1 Sutyrin Sergei - Professor, World Economy Department Head, WTO ChairHolder, St. Petersburg State University; Korgun Irina - HK research professor Asia Pacific Research Center (APRC), Hanyang University (Seoul, Korea). 